\title{
EARLY RESEARCH AND PATHOPHYSIOLOGY
}

\author{
By David WhitTeridge, D.M., F.R.S. \\ Professor of Physiology, University of Oxford
}

WHEN Ludwig Guttmann arrived in Oxford he was involved in research on peripheral nerve lesions with Eric Guttmann, Graham Weddell, Peter Medawar and J. Z. Young on work which was supported by the Peripheral Nerve Injuries Committee of the Medical Research Council. Ludwig published in 194I an account of the delimitation of areas of nerve distribution to the skin by sweating tests in man. A year later he published with colleagues an interesting and important paper which described the migration of nerve fibres from surrounding areas into a denervated area in the rabbit's foot. The whole question of nerve sprouting in these conditions is still a lively problem. He also published with J. Z. Young, Peter Medawar and Eric Guttmann a classical paper on the rate of regeneration of nerve fibres.

Brigadier George Riddoch was a member of the Peripheral Nerve Injuries Committee and had written with Henry Head the classical paper on reflexes from the isolated spinal cord in man during the 19I4-I8 War. It was decided in 1943 that special centres for spinal injuries should be set up, and Ludwig started the first one at Stoke Mandeville in February I944.

Later that year, orders were given that paraplegic patients from the D-day landings were to be sent to Stoke Mandeville. By August 1944 the Centre was in being with two wards full of paraplegics from Normandy of various levels and degrees of completeness. One of Ludwig's first battles was with the orthopaedic surgeons, who sent over patients on spinal plaster beds-designed to spread the weight of the patient and to prevent bed sores. In fact, patients wasted so rapidly that these patients arrived not merely with sacral, ischial and trochanteric sores, but with a separate pressure sore over each vertebral spine from the lumbar to the mid-thoracic region. At that time most of the orderlies had been released from the R.A.M.C., and Ludwig had to be in the wards every night until his orders were understood and obeyed, that patients were to be turned every 2 hours, and drainage tubes were not to be closed off to save the trouble of emptying bottles.

During that summer Ludwig noticed that some patients went red in the face when their bladders were washed out, that they had an ascending discomfort finishing with severe headache, blockage of the nasal passages and sweating. All these signs and symptoms subsided after the pressure in the bladder was released. Ludwig asked me to come over and measure skin temperature in this condition, which I did with home-made multiple thermo-junctions. When it was obvious that the blood pressure would have to be measured, it appeared that the wards did not possess a sphygmomanometer, and for our second experimental distension of the bladder we used Ludwig's own machine from Germany-a beautiful Pachon oscillometer. It was soon clear that only patients with lesions above T6 had sharp rises of blood pressure with their red faces and headaches, but that all patients vasoconstricted in the toes and legs when their bladders were distended, and that this was the basic disturbance. 
When we published in 1947-a year or so before rivals in the U.S.A.-we were not helped by a physician who later became a distinguished professor of medicine who referred to the effects of bladder distension as 'a bizarre phenomenon'. The individual components looked a little odd, but even at the time we claimed that it all made simple sense if one thought that the regulatory mechanisms for blood pressure and for body temperature had been grossly mutilated in the paraplegic by removal of a large proportion of the autonomic output, the principal effector pathway.

It is interesting to look back at textbooks and to see that though Claude Bernard had taught the importance of the constancy of the internal environment in I85I, it was not mentioned in Schäfer's Textbook of Physiology in 1900, nor in Bayliss's excellent Principles of General Physiology (1924), and was only revived in physiological circles by Haldane, Cannon and J. Barcroft in the thirties. As a concept it does not seem to have reached clinical medicine till the fifties as part of the enormous growth of physiologically based cardiovascular medicine and the increase in familiar servo-mechanisms in that decade. However, we did claim in I 947 that it was the disturbance of regulatory mechanisms of the whole body that one should worry about, and not merely catalogue the reflexes displayed by the isolated cord as had been done by Head and Riddoch in I9I7. Nowadays we should put it rather more grandiosely in terms of 'systems analysis', a method of dealing quantitatively with regulatory processes, and we would include the disturbances produced by noradrenaline liberation and probably by renin from the initially neurogenic hypertension.

Ludwig was brought up to believe that pathophysiology, the study of the disturbances of function in disease, was of fundamental importance. He had already conceived of bed sores as mechanically produced by a compressing force per unit area which occluded the skin capillaries, and treatment based on this simple idea and not, for example, on trophic nerves to the skin, had led to control and prevention. Here he had another example of a new phenomenon, bizarre when its details were looked at separately, easily grasped as a whole in terms of disordered regulation. This confirmed his determination to analyse and define disorders of paraplegics - their limitation in posture and movement, their urinary and sexual difficulties-in pathophysiological terms, and when so defined they became controllable. I am very proud to have been an early ancillary worker. 